\title{
SOCIOECONOMIC AND GENDER INEQUALITIES IN SMOKING. FINDINGS FROM THE CZECH NATIONAL TOBACCO SURVEYS 2012-2015
}

\author{
Ladislav Csémy 1, 2, Hana Sovinová1, Zuzana Dvořáková2 \\ ${ }^{1}$ National Institute of Public Health, Prague, Czech Republic \\ ${ }^{2}$ National Institute of Mental Health, Klecany, Czech Republic
}

\section{SUMMARY}

Objective: Smoking significantly affects morbidity and mortality of the population. The incidence of smoking is determined by gender and socioeconomic status (SES) of an individual. The aim of this study is to analyse the relationship between gender and SES indicators and smoking.

Methods: The analysis is based on data from the Czech National Tobacco Surveys from 2012 to 2015 (N 1,800 per year). The prevalence of smoking, average daily consumption of cigarettes, initiation ratio and quit ratio were monitored. Smoking habits of the respondents were surveyed using the Czech version of the standard Tobacco Questions for Surveys (TQS) questionnaire. SES was measured by a composite index comprising three variables (level of education, income and job prestige); it had four categories: low, lower-middle, upper-middle, and high.

Results: In comparison with women, men had a higher smoking prevalence $(\mathrm{OR}=1.41,95 \% \mathrm{Cl}=1.09-1.84)$, higher consumption of cigarettes $(B=4.11,95 \% \mathrm{Cl}=1.97-6.26)$, and higher rate of smoking initiation $(\mathrm{OR}=1.38,95 \% \mathrm{Cl}=1.10-1.74)$, but they did not differ in the quit rate $(\mathrm{OR}=0.85$, $95 \% \mathrm{Cl}=0.60-1.21)$. Persons in the low SES category had higher prevalence of smoking and higher initiation ratio compared with those in the high SES category $(\mathrm{OR}=2.59,95 \% \mathrm{Cl}=1.36-4.97 ; \mathrm{OR}=2.23,95 \% \mathrm{Cl}=1.26-3.95)$. Cigarette consumption and quit ratio did not differ according to SES. The prevalence of smoking in the years 2012-2014 did not differ; in 2015, it was lower compared to the previous three years.

Conclusions: Inequalities in socioeconomic status affect smoking, which significantly contributes to morbidity and mortality. Measures aimed at reducing inequalities in health must take into account both smoking as a risk factor and socioeconomic status, which affects its occurrence. Programmes to reduce tobacco use should reflect the different needs of individuals with different SES levels. It is especially necessary to seek effective approaches for smokers with low socioeconomic status.

Key words: smoking, socioeconomic status, prevalence, trends

Address for correspondence: L. Csémy, National Institute of Public Health, Šrobárova 48, 10042 Prague 10, Czech Republic. E-mail: Icsemy@ gmail.com

https://doi.org/10.21101/cejph.a4923

\section{INTRODUCTION}

Smoking is one of the world's most important factors affecting morbidity and mortality of the population. The WHO report states 5.1 million deaths attributable to smoking and the contribution of smoking to the annual mortality rate of $17.9 \%$ in high-income countries $(1,2)$. In the Czech Republic, the annual mortality associated with smoking is estimated at the level of 17-19\% (3-5). The most common causes of death are cardiovascular diseases and cancer (18,567 of 20,550 in 2000) (3).

The mortality rate is influenced by demographic characteristics of the population, especially gender and age, but also by the socioeconomic status (SES) $(6,7)$. In case of smoking attributable mortality, the differences arising from socioeconomic status are significant. Higher prevalence of smoking and thus higher mortality are stated in the group with low socioeconomic status $(6,8,9)$. Growing inequalities are associated with the growth of SES differences in smoking, resulting in health inequality as well.

Socioeconomic status is defined in studies differently. In the studies of smoking habits, the usual definition of socioeconomic status is the attained education or income (8-11). The level of education or income as indicators of SES apply well in societies where the education level is highly correlated with income and occupational status. In Central and Eastern Europe, which recently underwent social and economic transformation and where social stratification is still in progress, it is preferable to use the SES composite index, taking into account the level of education, income and occupational prestige. As for the construction of SES, no stable standard is available as for now. In this study, we were inspired by considerable domestic experience when creating the SES variable (12-15).

The analyses of socioeconomic status in relation to smoking are often limited to the relationship between SES and smoking at the moment. Schaap and Kunst (10) and Nagelhout et al. (11) stated in this respect that it is a narrow view that does not take into account the fact that the prevalence of current smoking is based both on the initiation and quit ratio. Moreover, the two latter characteristics have significant ties to the SES level and gender.

In order to reduce health risks, the World Health Organization (WHO) developed guidelines to effectively fight the smoking epidemic. The recommendations for tobacco control were summarized in the Global Adult Tobacco Survey Collaborative 
Group (MPOWER) document, which includes six major priorities for effective strategies (WHO, 2008): monitor tobacco use and prevention policies; protect people from tobacco smoke; offer assistance in quitting smoking; warn of the dangers of tobacco use; enforce a ban on tobacco advertising, promotion and sponsorship; and increase the tax burden on tobacco products. Monitoring smoking habits is the basis for the adoption of effective preventive and control measures. The need for monitoring led the WHO and CDC to develop a standardized questionnaire: Tobacco Questions for Surveys (TQS) consisting of key questions, which correspond to the priorities of MPOWER (16). The Working Group in the National Health Institute has monitored tobacco use in the Czech Republic since 1996; the standardized TQS questionnaire was included in the monitoring in 2012 (17).

The aim of this study is to analyse the development of smoking habits in the Czech adult population surveyed through the TQS questionnaire, with respect to gender and socioeconomic status. It is the first study to analyse a wider range of smoking habits (current smoking, cigarette consumption, initiation and quit ratio) in relation to the composite index of socioeconomic status.

\section{MATERIALS AND METHODS}

\section{Sample}

Data come from the Czech National Tobacco Survey carried out from 2012 to 2015 . The sample characteristics are summarized in Table 1. The selection technique was the same each year and represented a combination of random selection of electoral districts from the complete list and quota sampling when interviewers addressed respondents in their homes at addresses according to a predetermined path. 10 interviews were performed in one electoral district. The interviews were carried out by trained interviewers.

\section{Questionnaire}

Smoking habits were detected using the Czech version of the standardized Tobacco Questions for Surveys (TQS) questionnaire (18). The following individual indicators of smoking behaviour were monitored: current smoker, daily smoker, ex- smoker, non-smoker, and lifelong non-smoker. Furthermore, we recorded the consumption of cigarettes (the average number of cigarettes smoked per day), the initiation rate (defined as the ratio of current and former smokers to all respondents) and the quit rate (defined as the ratio of ex-smokers to current smokers and ex-smokers).

\section{Measurement of Socioeconomic Status}

The SES variable was constructed as a composite index of the three original variables in the questionnaire. The first of these variables, the level of education (primary, secondary/apprenticeship, upper secondary and higher), the second variable, the net income of household (8 categories from 10,000 CZK (approx. €400) to CZK 70,000 (approx. €2,800) and more). The last variable was the profession, which was originally divided into 16 categories, but we recoded it in 4 groups: the highest group included occupations requiring university education and representing a senior management position, the lowest group included occupations requiring no professional qualifications and low responsibility (auxiliary manual jobs). The categories were derived using the same algorithm for each file (years 2012-2015). The group with high SES was defined by higher education, highincome category and occupations that require high qualifications and are associated with high prestige (e.g. company director). The low SES category included persons with low education, low income and an occupation with minimal qualifications. The composite index worked with four categories (low SES, lower middle, upper middle, and high SES). The analyses using SES are limited to the age group of 25-64 years, i.e. the economically active population.

\section{Statistical Analyses}

The basic overview of smoking habits is stated as the prevalence value with the respective confidence intervals that allow to assess the significance of difference in terms of prevalence by gender and the year of study. The differences in smoking behaviour indicators were tested using logistic regression for cases, where the dependent variable was current smoking, daily smoking, initiation rate, and quit rate. Linear regression was applied with cigarette consumption as the dependent variable.

Table 1. Sample characteristics

\begin{tabular}{|c|c|c|c|c|}
\hline Study year & $\begin{array}{c}2012 \\
(N=1,802)\end{array}$ & $\begin{array}{c}2013 \\
(\mathrm{~N}=1,797)\end{array}$ & $\begin{array}{c}2014 \\
(N=1,810)\end{array}$ & $\begin{array}{c}2015 \\
(N=1,798)\end{array}$ \\
\hline \multicolumn{5}{|l|}{ Gender $(\%)$} \\
\hline Males & 48.8 & 48.6 & 48.6 & 48.2 \\
\hline Females & 51.2 & 51.4 & 51.4 & 51.8 \\
\hline Age group 25-64 (\% of the whole sample) & 67.8 & 67.4 & 67.2 & 67.3 \\
\hline \multicolumn{5}{|l|}{ Socioeconomic status (\%) } \\
\hline Low & 13.8 & 6.9 & 16.0 & 12.2 \\
\hline Lower Middle & 40.3 & 43.6 & 46.9 & 31.0 \\
\hline Upper Middle & 32.9 & 35.5 & 28.5 & 47.2 \\
\hline High & 13.0 & 14.0 & 8.7 & 9.5 \\
\hline
\end{tabular}




\section{RESULTS}

Gender Differences in Smoking Habits in 2012-2015

The variability in smoking habits is summarized in Table 2. In addition, prevalence rates include the lower and upper limits of the confidence intervals, allowing for quick assessment of the significance of differences in the prevalence estimates. It turns out that there are only small differences in the smoking habits of the population during the years 2012-2014. The smoking prevalence was significantly lower in 2015 when compared with 2012-2014, both in men and women. The entire period may be summarized by stating that there are fewer women than men among daily smokers and, vice versa, women predominate in the lifelong non-smokers group. The proportion of female ex-smokers is lower than that of men, but the difference was statistically significant only in 2013 .

\section{Socioeconomic Status and Smoking Habits}

Selected characteristics of smoking in relation to SES are visualized in Figure 1. The graph shows that the categories of low and lower middle SES are associated with a higher prevalence of smoking, higher initiation ratio and lower quit ratio, although this relationship is not entirely consistent in each measurement year. Regarding the consumption of cigarettes, the relationship with SES is ambiguous, except for the obvious decline in cigarette consumption in the high SES group.

\section{Impact of SES on Smoking Habits Based on Data from 2015 Survey}

The influence of SES category on the smoking habits in the data from 2015 was analysed using regression models. The results are summarized in Table 3. SES significantly differ in terms of the proportion of current smokers. Compared to the group with the highest SES, smoking is more prevalent in lower SES categories. OR values for lower middle and low SES are 2.02 and 2.6 , respectively. Also the relationship of genders is statistically significant, where men are more likely to smoke than women (OR $=1.4$ ). The stated OR values are also statistically significant in case of daily smoking, but significantly higher compared to current smokers (including occasional smokers). Linear regression was used to analyse the relationship between cigarette consumption, SES categories and gender. While SES categories did not differentiate between consumption, women had a significantly lower consumption than men, as expected $(\mathrm{B}=-4.11,95 \% \mathrm{CI}$ $-6.26,-1.97)$. Initiation ratio increased inversely with the level of SES: the group of people with low SES had an initiation ratio 2.5 times higher than the high SES group. The highest quit ratio was found in the high SES group, but the differences in the quit

Table 2. Prevalence of smoking in per cents (95\% Cl), 2012-2015

\begin{tabular}{|c|c|c|c|c|}
\hline & Year & Total & Males & Females \\
\hline \multirow{4}{*}{ Current smokers } & 2015 & $24.1(22.1 ; 26.1)$ & $27.3(24.4 ; 30.5)$ & $21.0(18.5 ; 23.8)$ \\
\hline & 2014 & $31.4(29.3 ; 33.6)$ & $37.4(34.2 ; 40.7)$ & $25.8(23.0 ; 28.7)$ \\
\hline & 2013 & $29.9(27.8 ; 32.1)$ & $36.4(33.2 ; 39.7)$ & $23.7(21.0 ; 26.6)$ \\
\hline & 2012 & $31.3(29.2 ; 33.5)$ & $36.5(33.4 ; 39.8)$ & $26.3(23.5 ; 29.3)$ \\
\hline \multirow{4}{*}{ Daily smokers } & 2015 & $18.2(16.5 ; 20.1)$ & $21.8(19.1 ; 24.7)$ & $14.8(12.6 ; 17.3)$ \\
\hline & 2014 & $23.5(21.6 ; 25.5)$ & $28.2(25.3 ; 31.3)$ & $19.0(16.6 ; 21.7)$ \\
\hline & 2013 & $22.2(20.3 ; 24.2)$ & $27.2(24.3 ; 30.3)$ & $17.4(15.1 ; 20.1)$ \\
\hline & 2012 & $23.1(21.2 ; 25.1)$ & $26.7(23.9 ; 29.8)$ & $19.6(17.1 ; 22.4)$ \\
\hline \multirow{4}{*}{$\begin{array}{l}\text { Irregular smokers } \\
\text { (non-daily smokers) }\end{array}$} & 2015 & $5.9(4.9 ; 7.1)$ & $5.5(4.2 ; 7.3)$ & $6.2(4.8 ; 8.0)$ \\
\hline & 2014 & $8.0(6.8 ; 9.3)$ & $9.2(7.4 ; 11.4)$ & $6.8(5.3 ; 8.6)$ \\
\hline & 2013 & $7.7(6.5 ; 9.0)$ & $9.2(7.4 ; 11.3)$ & $6.3(4.8 ; 8.1)$ \\
\hline & 2012 & $8.2(7.0 ; 9.6)$ & $9.8(7.9 ; 12.0)$ & $6.7(5.2 ; 8.6)$ \\
\hline \multirow{4}{*}{ Current non-smokers } & 2015 & $75.9(73.9 ; 77.9)$ & $72.7(69.5 ; 75.6)$ & $79.0(76.2 ; 81.5)$ \\
\hline & 2014 & $68.6(66.4 ; 70.7)$ & $62.6(59.3 ; 65.8)$ & $74.2(71.3 ; 77.0)$ \\
\hline & 2013 & $70.1(67.9 ; 72.2)$ & $63.6(60.3 ; 66.8)$ & $76.3(73.4 ; 79.0)$ \\
\hline & 2012 & $68.7(66.5 ; 70.8)$ & $63.5(60.2 ; 66.7)$ & $73.7(70.7 ; 76.5)$ \\
\hline \multirow{4}{*}{ Former smokers } & 2015 & $17.2(15.5 ; 19.0)$ & $18.1(15.6 ; 20.9)$ & $16.3(14.0 ; 18.9)$ \\
\hline & 2014 & $14.7(13.1 ; 16.4)$ & $15.5(13.2 ; 18.1)$ & $13.8(11.7 ; 16.3)$ \\
\hline & 2013 & $12.6(11.1 ; 14.2)$ & $15.1(12.8 ; 17.7)$ & $10.2(8.4 ; 12.4)$ \\
\hline & 2012 & $13.1(11.6 ; 14.8)$ & $14.6(12.3 ; 17.1)$ & $11.7(9.7 ; 14.0)$ \\
\hline \multirow{4}{*}{ Lifetime non-smokers } & 2015 & $58.7(56.4 ; 61.0)$ & $54.6(51.2 ; 57.9)$ & $62.6(59.4 ; 65.7)$ \\
\hline & 2014 & $53.9(51.6 ; 56.2)$ & $47.1(43.8 ; 50.5)$ & $60.4(57.1 ; 63.5)$ \\
\hline & 2013 & $57.5(55.2 ; 59.8)$ & $48.5(45.2 ; 51.9)$ & $66.1(63.0 ; 69.1)$ \\
\hline & 2012 & $55.6(53.3 ; 57.9)$ & $48.9(45.6 ; 52.3)$ & $62.0(58.7 ; 65.1)$ \\
\hline
\end{tabular}


ratios between individual SES categories did not reach statistical significance. Gender showed no effect on the quit ratio either.

\section{DISCUSSION}

The study results confirm the higher incidence of smoking among men. This difference was six to twelve percent between 2012 and 2015. The prevalence of smoking, with the exception of 2015 , fluctuated and the differences did not reach statistical significance. The results of the survey in the coming years will show whether the lower prevalence of smoking in 2015 is a permanent change or a short-term fluctuation. The observation period is short and allows only for cautious conclusions. The observed prevalence of smoking altogether corresponds with other studies carried out in the Czech Republic. Two nationwide surveys were conducted in 2008: a study of the National Monitoring Centre focused on drugs abuse and the European Health Interview Survey (EHIS) of the Institute of Health Information and Statistics $(19,20)$. According to these studies, daily smoking in men was $36 \%$ and $30 \%$, respectively, and in women $21 \%$ and $19 \%$, respectively. The newer EHIS 2014 study showed a lower prevalence of daily smoking, $27 \%$ in men and $16 \%$ in women (21). These values are comparable with the results of our study from 2014. Similar differences in smoking in men and women as in the Czech Republic were found in the neighbouring countries.

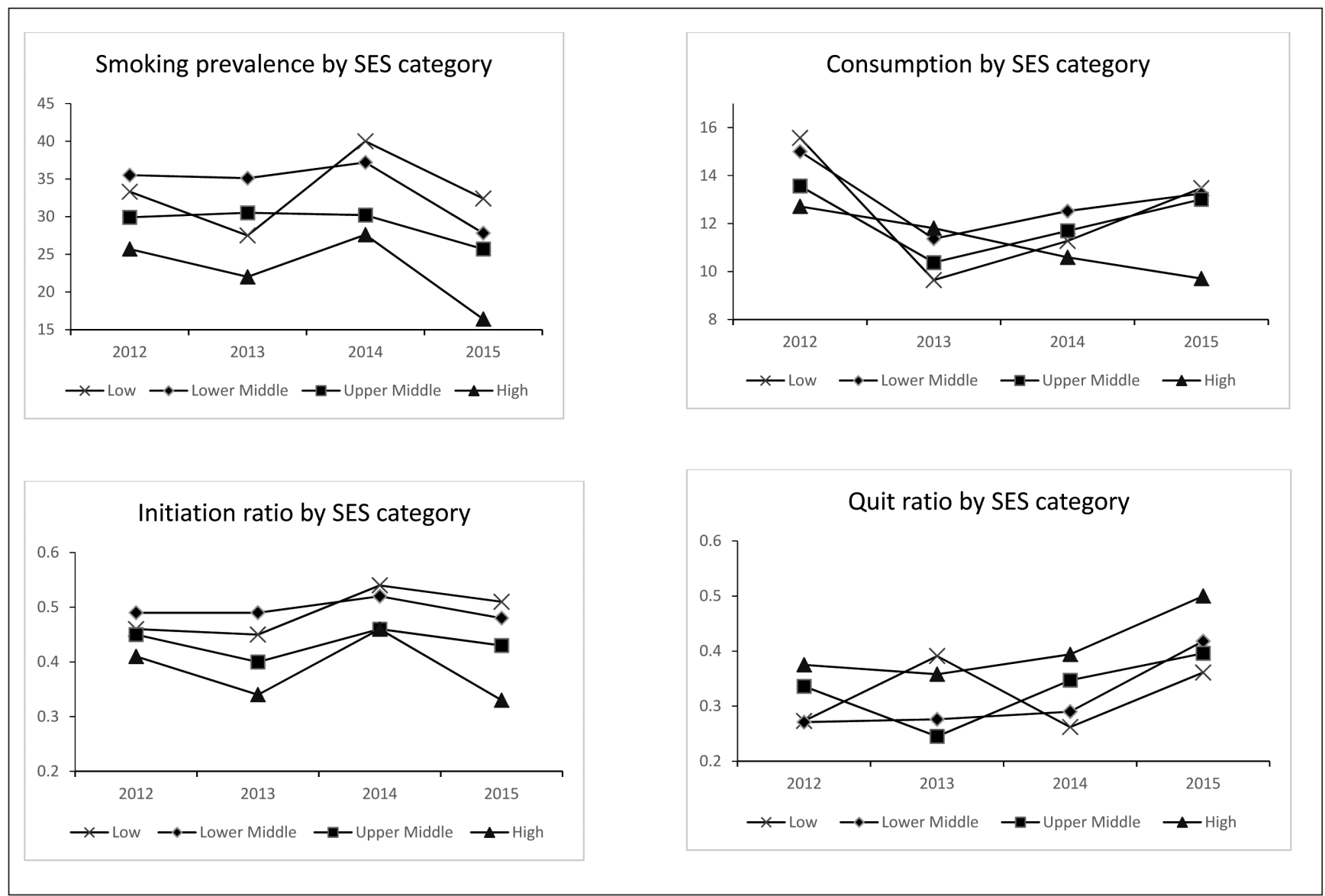

Fig. 1. Smoking prevalence (\%), cigarette consumption (mean number of cigarettes per day), initiation ratio, and quit ratio by socioeconomic status and the year of study.

Table 3. SES and gender as predictors of smoking related outcomes

\begin{tabular}{|l|c|c|c|c|c|}
\hline & Current smoker $^{\mathrm{a}}$ & Daily smoker $^{\mathrm{a}}$ & Smoking consumption $^{\mathrm{b}}$ & Initiation ratio $^{\mathrm{a}}$ & Quit ratio $^{\mathrm{a}}$ \\
\hline SES & $2.60(1.36 ; 4.97)^{*}$ & $3.27(1.61 ; 6.65)^{*}$ & $1.41(-2.50 ; 5.31)$ & $2.23(1.26 ; 3.95)^{*}$ & $0.56(0.23 ; 1.32)$ \\
\hline Low & $2.02(1.25 ; 3.27)^{*}$ & $2.40(1.39 ; 4.14)^{*}$ & $0.72(-1.65 ; 3.08)$ & $1.93(1.30 ; 2.86)^{*}$ & $0.73(0.39 ; 1.35)$ \\
\hline Lower Middle & $1.80(1.15 ; 2.82)^{*}$ & $1.79(1.06 ; 3.00)^{*}$ & 0.00 & $1.54(1.08 ; 2.22)^{*}$ & $0.67(0.37 ; 1.19)$ \\
\hline Upper Middle & 1.00 & 1.00 & $-2.81(-6.88 ; 1.26)$ & 1.00 & 1.00 \\
\hline High & $1.41(1.09 ; 1.84)^{*}$ & $1.59(1.18 ; 2.12)^{*}$ & 0.00 & $1.38(1.10 ; 1.74)^{*}$ & $0.85(0.60 ; 1.21)$ \\
\hline Gender & 1.00 & 1.00 & $-4.11(-6.26 ;-1.97)^{*}$ & 1.00 & 1.00 \\
\hline Males & \multicolumn{7}{|c|}{}
\end{tabular}

${ }^{a}$ Odds ratios and $95 \%$ confidence intervals; ${ }^{\circ}$ Betas and $95 \%$ confidence intervals; *Regression coefficient significant at $p<0.01$ 
For example, in Germany in 2012, $24.5 \%$ of men and $18.7 \%$ of women were daily smokers (22). In Poland in 2009, the same parameters were $35.8 \%$ and $22.1 \%$, respectively (23).

The relationship between the SES level and the prevalence of smoking was indirect. In the present, smoking in the group of low SES and lower middle SES is 2 times and 2.5 times more common, respectively, than in the high SES group. The incidence of daily smoking was three times higher in the low SES group than in the high SES group. Similar findings were also reported in recent foreign studies (24-26). A British study from 2009 showed that $25 \%$ of blue-collar workers were smokers, while only $16 \%$ of white-collar workers (27). Dutch researchers studied the relationship between the prevalence of smoking and the education and income levels from 2001 to 2008. The high-income group and the group with high levels of education smoked significantly less than the other groups (11). One of the few studies that does not support the above findings compares the initiation of smoking among women in five European countries, including the Czech Republic (28). However, the authors themselves point out that the difference may be caused by inappropriately selected SES indicators.

Other smoking outcome indicators are included in fewer reports, compared with the prevalence of smoking. We found no statistically significant relationship with the SES categories for cigarette consumption. It means that adult smokers smoked approximately the same amounts of cigarettes, regardless of income, education and occupational status, with the only difference found in lower consumption in female smokers than in men. The results of international studies are not consistent in terms of the relationship between consumption and socioeconomic status. The already mentioned Dutch study (11) shows an increased consumption among smokers in the lower socioeconomic group. However, the study of Hiscock et al. (8) states the opposite - heavy smoking is associated with high SES in developed countries.

The initiation ratio, i.e. the ratio of current and former smokers to all respondents in that category, was significantly higher in our study in low SES and lower-middle SES categories. The significance of the initiation ratio is explained by the association with the higher smoking prevalence and higher initiation. People with higher SES started to smoke less often than those with low SES, and thus have a lower prevalence of smoking. The initiation of smoking occurs in adolescence with the simultaneous effect of multiple factors, such as parental patterns, group social norms, availability of cigarettes at home and in the region, or even the lower ability of adolescents growing up in disadvantaged conditions to resist peer pressure or marketing.

The last of the monitored indicators, quit ratio, was investigated to find out whether the tendency to quit smoking varies by the SES level. We assumed that the quit ratio will be higher in the high SES group than in other groups. This was confirmed, but the differences did not reach statistically significant levels.

\section{Study Limitations}

The limitations of the study lie in its nature - a cross-sectional survey may be influenced by the ability to recall and, in some respects, even by social desirability (e.g. the willingness to admit the level of income). The second limiting condition is the cohort size in those years. Restricting the cohort to the economically active population aged 25-64 years would lead to low numbers in some subgroups in the analysis of smoking for the four SES categories and gender and limited statistical evaluation possibilities. Therefore, no regression analysis separately for gender was performed.

\section{CONCLUSIONS}

Our study confirmed that the composite index of socioeconomic status, reflecting the level of education, income and position in employment, is a useful measure in the analysis of smoking prevalence and other associated indicators. The results show that inequality in socioeconomic status affects smoking, which significantly contributes to morbidity and mortality. Inequality in health is, to a large extent, determined by disparities in socioeconomic status. Measures aimed at reducing inequalities in health must take into account smoking as a risk factor and the socioeconomic status, which affects its occurrence. Programmes to reduce tobacco use should reflect the different needs of individuals with different SES levels. It is especially necessary to seek effective approaches for smokers with low socioeconomic status. Research in this area, although scarce, emphasise the importance of strengthening the motivation to quit smoking, the availability of pharmacotherapy, psychological support and counselling on the individual level and community-based campaigns increasing the understanding of the health risks associated with smoking and general population (national) level reduction of the availability of cigarettes through pricing measures and distribution points restrictions.

\section{Acknowledgements}

This study has been supported by grant from the Ministry of Health of the Czech Republic MZ ČR - RVO 75010330 and by the project \# LO1611 with financial support from the MEYS under NPU program for the National Institute of Mental Health.

\section{REFERENCES}

1. World Health Organization. Global health risks: mortality and burden of disease attributable to selected major risks. Genava: WHO; 2009.

2. Peto R, Lopez AD, Boreham J, Thun, M. Mortality from smoking in developed countries 1950-2005 (or later). Population. 2012;251351(103074):112996.

3. Sovinová H, Csémy L, Procházka B, Kottnauerová S. Smoking attributable mortality in the Czech Republic. J Public Health. 2008;16(1):37-42.

4. Peto R, Lopez AD, Boreham J, Thun M, Heath Jr C. Mortality from Smoking in Developed Countries 1950-2000. 2nd ed. Oxford: Oxford University Press; 2003.

5. Sovinová H, Csémy L, Procházka B, Kottnauerová S. Smoking attributable hospital treatment, treatment costs and smoking attributable mortality in the Czech Republic in 2002. Cent Eur J Public Health. 2007;15(2):7983.

6. Phelan JC, Link BG, Diez-Roux A, Kawachi I, Levin B. "Fundamental causes" of social inequalities in mortality: a test of the theory. J Health Soc Behav. 2004;45(3):265-85.

7. Jha P, Peto R, Zatonski W, Boreham J, Jarvis MJ, Lopez AD. Social inequalities in male mortality, and in male mortality from smoking: indirect estimation from national death rates in England and Wales, Poland, and North America. Lancet. 2006;368(9533):367-70.

8. Hiscock R, Bauld L, Amos A, Fidler JA, Munafò M. Socioeconomic status and smoking: a review. Ann N Y Acad Sci. 2012;1248:107-23.

9. Hrubá F, Fabiánová E, Bencko V, Cassidy A, Lissowska J, Mates D, et al. Socioeconomic indicators and risk of lung cancer in central and Eastern Europe. Cent Eur J Public Health. 2009;17(3):115-21. 
10. Schaap MM, Kunst AE. Monitoring of socio-economic inequalities in smoking: learning from the experiences of recent scientific studies. Public Health. 2009 Feb;123(2):103-9.

11. Nagelhout GE, de Korte-de Boer D, Kunst AE, van der Meer RM, de Vries H, van Gelder BM, et al. Trends in socioeconomic inequalities in smoking prevalence, consumption, initiation, and cessation between 2001 and 2008 in the Netherlands. Findings from a national population survey. BMC Public Health. 2012;12:303. doi: 10.1186/1471-2458-12-303.

12. Hampl M. Regional differentiation of current socio-economic development in the Czech Republic. Czech Soc Rev. 2007; 43(05):889-910. (In Czech)

13. Kreidl M, Hošková L. Strategies for measuring socioeconomic status and health status in sociological texts. Data a výzkum-SDA Info. 2008;2(2):131-54. (In Czech.)

14. Šplíchalová A, Šlachtová H. Lifestyle and socio-economic factors in relation to health as the subject of interest in epidemiological and sociological studies. In: Living conditions and health; 2010 Oct 15-17; Štrbské Pleso, Slovakia. (In Czech.)

15. Šafr J. New and alternative approaches in measurement of vertical social structure. Data a výzkum-SDA Info. 2005;7(1):12-4. (In Czech.)

16. World Health Organization. WHO report on the global tobacco epidemic. The MPOWER package. Geneva: WHO; 2008.

17. Sovinová H, Csémy L, Kernová, V. Tobacco and alcohol abuse in the Czech Republic: report on the situation over the past ten years. Prague: National Institute of Public Health; 2014. (In Czech.)

18. Kalsbeek WD, Bowling JM, Hsia J, Mirza S, Palipudi KM, Asma S. The Global Adult Tobacco Survey (GATS): sample design and related methods. In: Proceedings of the section on survey methods, joint statistical meetings; 2010

19. Běláčková V, Nechanská B, Chomynová $P$, Horáková M. General population survey on substance use and attitudes towards it in the Czech Republic in 2008. Prague: Government of the Czech Republic; 2012. (In Czech.)
20. Kasalová-Daňková Š, Holub J, Láchová J. European Health Interview Survey in the Czech Republic EHIS 2008. Prague: Institute of Health Information and Statistics of the Czech Republic; 2011. (In Czech.)

21. EHIS 2014 - Basic survey results [Internet]. Prague: Institute of Health Information and Statistics of the Czech Republic; 2015 [cited 2016 Sep 8]. Available from: http://www.uzis.cz/node/7495. (In Czech.)

22. Giskes K, Kunst AE, Benach J, Borrel C, Costa G, Dahl E, et al. Trends in smoking behaviour between 1985 and 2000 in nine European countries by education. J Epidemiol Community Health. 2005;59(5):395-401.

23. Kaleta D., Usidame B, Dziankowska-Zaborszczyk E, MakowiecDąbrowska T, Leinsalu M. Prevalence and factors associated with hardcore smoking in Poland: findings from the Global Adult Tobacco Survey (2009-2010). BMC Public Health. 2014;14:583. doi: 10.1186/1471-245814-583.

24. Pierce JP, Fiore MC, Novotny TE, Hatziandreu EJ, Davis RM. Trends in cigarette smoking in the United States. Educational differences are increasing. JAMA. 1989;261(1):56-60.

25. Smith P, Frank J, Mustard C. Trends in educational inequalities in smoking and physical activity in Canada: 1974-2005. J Epidemiol Community Health. 2009;63(4):317-23

26. World Health Organization. WHO global report on trends in prevalence of tobacco smoking 2015. Genava: WHO; 2015.

27. Robinson S, Lader D. General Household Survey 2007: smoking and drinking among adults. Nevport: Office for National Statistics; 2009.

28. Oh DL, Heck JE, Dresler C, Allwright S, Haglund, M., Del Mazo SS, et al. Determinants of smoking initiation among women in five European countries: a cross-sectional survey. BMC Public Health. 2010;10:74. doi: $10.1186 / 1471-2458-10-74$

Received September 8, 2016 Accepted in revised form March 20, 2018 